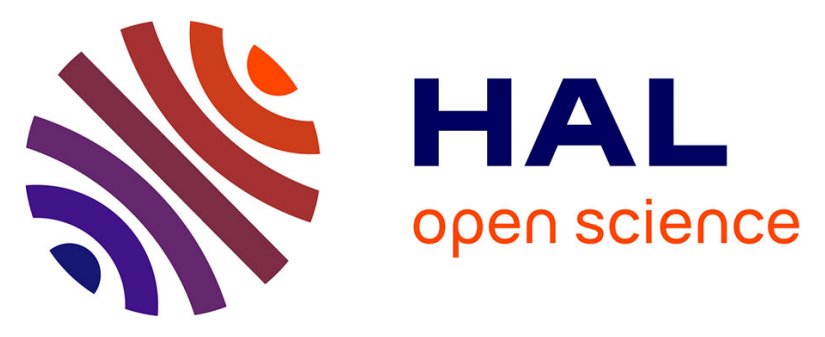

\title{
Prophylactic neck dissection for low-risk differentiated thyroid cancers: Risk-benefit analysis
}

\author{
Xavier Dubernard, Sandrine Dabakuyo, Samiratou Ouédraogo, Koceila \\ Amroun, David Kere, Talal Nasser, Sophie Deguelte, Jean-Marie Pochart, \\ Jean-Claude Mérol, Marc Makeieff, et al.
}

\section{To cite this version:}

Xavier Dubernard, Sandrine Dabakuyo, Samiratou Ouédraogo, Koceila Amroun, David Kere, et al.. Prophylactic neck dissection for low-risk differentiated thyroid cancers: Risk-benefit analysis. Archives of Otorhinolaryngology - Head \& Neck Surgery, 2016, 38 (7), pp.1091-1096. 10.1002/hed.24402 . hal02453755

\section{HAL Id: hal-02453755 \\ https://hal.univ-reims.fr/hal-02453755}

Submitted on 4 Jun 2020

HAL is a multi-disciplinary open access archive for the deposit and dissemination of scientific research documents, whether they are published or not. The documents may come from teaching and research institutions in France or abroad, or from public or private research centers.
L'archive ouverte pluridisciplinaire HAL, est destinée au dépôt et à la diffusion de documents scientifiques de niveau recherche, publiés ou non, émanant des établissements d'enseignement et de recherche français ou étrangers, des laboratoires publics ou privés. 


\title{
Prophylactic neck dissection for low-risk differentiated thyroid cancers: Risk-benefit analysis
}

\author{
Xavier Dubernard, MD, ${ }^{1,2 \star}$ Sandrine Dabakuyo, PharmD, PhD, ${ }^{1}$ Samiratou Ouedraogo, PharmD, PhD, ${ }^{1}$ Koceila Amroun, MD, ${ }^{3}$ David Kere, MD, ${ }^{\dagger \dagger}$ \\ Talal Nasser, MD, ${ }^{4}$ Sophie Deguelte, MD, ${ }^{5}$ Jean-Marie Pochart, MD, ${ }^{1}$ Jean-Claude Merol, MD, ${ }^{2}$ Marc Makeieff, MD, PhD, ${ }^{2}$ André Chays, MD, PhD, ${ }^{2}$ \\ Claire Schvartz, MD' \\ ${ }^{1}$ Thyroïde Marne-Ardennes Register, CLCC Institut Jean Godinot, Reims, France, ${ }^{2}$ Otolaryngology Department, Centre Hospitalier Robert Debré, Reims, France, ${ }^{3}$ General Surgery \\ Department, CLCC Institut Jean Godinot, Reims, France, ${ }^{4}$ Otolaryngology Department, Polyclinique de Courlancy, Reims, France, ${ }^{5}$ General Surgery Department, Centre Hospitalier \\ Robert Debré, Reims, France.
}

Accepted 29 December 2015

Published online 13 February 2016 in Wiley Online Library (wileyonlinelibrary.com). D0l 10.1002/hed.24402

ABSTRACT: Background. The benefit of neck dissection is the subject of debate in differentiated thyroid cancer (DTC). We analyze the riskbenefit of neck dissection for low-risk DTC without detectable lymph nodes.

Methods. We conducted a retrospective study from 1983 to 2003; which included 295 patients without detectable lymph nodes who were treated by thyroidectomy with $(\mathrm{C}+$ ) or without $(\mathrm{C}-)$ neck dissection. All patients had iodine131 therapy. We compared the frequency of remission, disease progression, and permanent complications between groups.

Results. Two hundred twelve patients comprised the $\mathrm{C}+$ group, and 83 patients the $\mathrm{C}$ - group. Respectively for $\mathrm{C}+$ versus $\mathrm{C}$-, remission rates were $92 \%$ versus $89.2 \%(p=.40)$, and progressive disease observed was $3.3 \%$ versus $7.2 \%(p=.10)$. Permanent hypoparathyroidism occurred in $15.1 \%$ in $\mathrm{C}+$ versus $3.6 \%$ in $\mathrm{C}-(p=.006)$.

Conclusion. The risk-benefit analysis of neck dissection in patients with low-risk DTC shows no benefit in terms of complete remission or occurrence of progression. However, risk of complications seems to be higher in patients with neck dissection. (c) 2016 Wiley Periodicals, Inc. Head Neck 38: 1091-1096, 2016

KEY WORDS: prophylactic, dissection, low-risk, thyroid, cancers

\section{INTRODUCTION}

Thyroid nodules are common in the general population. Some autopsy series ${ }^{1}$ report that their frequency increases with age and may be $>50 \%$ after 50 years of age. These nodules are often discovered during cervical palpation ( $4 \%$ to $8 \%$ of cases), cervical ultrasonography (10\% to $41 \%$ of cases), ${ }^{2-5}$ or during an imaging study performed for another pathology (from 1.1\% to $2.9 \%$ in the positron emission tomography-fluorodeoxyglucose). ${ }^{6}$ The frequency of differentiated thyroid cancer (DTC) in these nodules ranges from $5 \%$ to $10 \%^{7}$ and these tumors count among the most common malignant endocrine tumors. ${ }^{8}$

The prognosis of DTC is excellent with disease-specific and overall survival $>90 \%$ at 10 years. ${ }^{8}$ The treatment is surgical and based primarily on thyroidectomy. ${ }^{9}$ The benefit of neck dissection in the absence of detectable lymph nodes remains the subject of some debate in tumors measuring $<40 \mathrm{~mm}$. In this population, the frequency of lymph node involvement proved by the pathological assessment, in the absence of lymph nodes detected pre-

*Corresponding author: X. Dubernard, Otolaryngology Department, Centre Hospitalier Robert Debré, Rue du Général Kœenig, 51100 Reims, France. E-mail: xavierdubernard@hotmail.fr

${ }^{\dagger}$ Deceased. operatively either clinically or by ultrasound, ranges from $35 \%$ to $72.7 \%$ depending on the series. ${ }^{10,11}$ However, for most authors, this lymph node involvement is not a risk factor for reduced survival in these patients. Thus, the recommendations of the American Thyroid Association (ATA) from 2009 do not recommend prophylactic neck dissection in these low-risk patients when no lymph node involvement is detectable preoperatively (recommendation rating C). ${ }^{12}$

Therefore, the main purpose of this study was to determine the utility of prophylactic cervical neck dissection in this population of patients treated for a thyroid nodule suspected to be malignant and measuring $\leq 40 \mathrm{~mm}$ without preoperative or intraoperative detected lymph nodes.

\section{MATERIALS AND METHODS}

\section{Population}

This was a retrospective, single-center study examining the records of 1260 patients, all primary thyroid tumor histologies combined, from 1983 to 2003 from the Marne-Ardennes Registry specializing in thyroid cancer. At the time (1983-2003), the protocol for surgical management implemented by surgeons in our region recommended systematic total thyroidectomy with central and lateral neck dissection association. Neck dissection was indicated when the diagnosis of cancer was established, 
namely either before surgery, or during surgery on extemporaneous examination of suspicious thyroid nodules if the tumor size was $>10 \mathrm{~mm}$.

All patients included in this study were over 18 years of age, had a thyroid nodule measure $\leq 40 \mathrm{~mm}$ in size with $\mathrm{T} 1$ or $\mathrm{T} 2$ disease, and were suspected of being a DTC either by preoperative cytology or during extemporaneous examination. No patient had signs of cervical lymph node involvement, clinically and/or ultrasonographically during the preoperative examination (N0), and no clinical suspicion of distant metastases (M0).

The patients included in this study underwent surgery, namely total thyroidectomy with prophylactic neck dissection ( $\mathrm{C}+$ group) or without prophylactic neck dissection (C- group). All patients were treated with only one ablative dose of 100 mci of ${ }^{131} \mathrm{I}$. When neck dissection was performed, it was always selective and involved the central compartment (VIa or VIb) and/or lateral compartment (III, IV, or Vb). Only well-differentiated intrathyroid cancers, pT1 and pT2, M0 (TNM classification $2010^{13}$ ), were selected for the study.

For each patient, we recorded the following variables: age at diagnosis, sex, histological type, tumor size in millimeters, multifocality, existence, and type of a dissection, number of lymph nodes removed and involved, and existence of complications and progressive disease.

\section{Follow-up, complications, and complete remission}

All patients were followed up according to the same protocol, in the same center, with an examination 6 to 8 months after surgery to determine whether or not there was complete remission. Then, a clinical follow-up, ultrasound imaging, and thyroglobulin test were performed once a year for 5 years, then at 7 years and 10 years after surgery, and then every 5 years thereafter. For each patient, the existence of complete remission, progressive disease, or cancer-related death was investigated. Secondary complications because of surgery were also recorded, as defined below.

Complete remission was defined 6 to 8 months after surgery as a normal clinical examination, a thyroid ultrasound without any detectable thyroid remnant and/or lymph nodes, and an undetectable level of thyroglobulin and antithyroglobulin antibodies with a high level of thyroid-stimulating hormone $>30 \mathrm{mUI} / \mathrm{L}$. If any one or more of these criteria were absent, then the patient was considered to have persistent disease.

Progressive disease was defined as the death of the patient directly related to DTC or documented recurrence with scintigraphical and/or cytological and/or histological and/or biological evidence, whether tumor-related, nodal, or metastatic (recurrent disease).

Complications occurring immediately after surgery were compressive cervical hematomas and cervical lymphatic effusions. We investigated the occurrence of recurrent laryngeal nerve paralysis or spinal accessory nerve injury up to 6 months after the intervention and we investigated the existence of permanent hypoparathyroidism (persistence of hypocalcemia requiring medical treatment) up to 1 year after surgery.

Excluded from this study were juvenile patients (aged $<18$ years) and patients who had a history of cervical radiation therapy, head and neck cancers, cervical neck dissection, thyroid cancer measuring $>40 \mathrm{~mm}$ or with aggressive histology, extrathyroidal extension, metastases, preoperative clinically and/or ultrasonographically detected lymphadenopathy, recurrent laryngeal nerve paralysis, spinal accessory nerve injury, or hypoparathyroidism or hyperparathyroidism known before surgery.

No patients were lost to follow-up. Patients and their doctors were contacted by mail when necessary to obtain follow-up information. Patients who moved to a different region were followed up by their local correspondents whose reports were sent to the Marne-Ardennes Thyroid Cancer Registry and indexed in the patient's file.

\section{Statistical Methods}

A descriptive analysis was performed for all variables available in the population. Quantitative variables were described using mean $( \pm \mathrm{SD})$, or median and range, and qualitative variables are described using frequencies and percentages. The characteristics of $\mathrm{C}+$ and $\mathrm{C}$ - patients were compared using the Student $t$ or Mann-Whitney tests for quantitative variables, and by the chi-square or Fisher's exact tests for qualitative variables, as appropriate.

\section{RESULTS}

\section{Characteristics of the population studied}

In total, 295 patients were included in this study. The mean age was $47 \pm 13.6$ years (range, 19-79 years) and the majority were women $(81.7 \%)$. Mean tumor size was $23.4 \pm 9.3 \mathrm{~mm}$ (range, $10-40 \mathrm{~mm} ; 9.2 \%$ of the tumors were equal to $10 \mathrm{~mm}$ ), with predominantly unifocal $(67.1 \%)$ and papillary $(78.3 \%)$ forms (Table 1$)$.

Two hundred twelve patients underwent neck dissection (C+ group), of whom 72 (34\%) had lymph node involvement. Twenty-nine patients $(13.7 \%)$ had suspicious lymph nodes found during the operation, and 21 of 29 were confirmed with intraoperative frozen section biopsy.

A total of 83 patients did not undergo neck dissection because of refusal of the management protocols (Cgroup).

The overall median follow-up duration was 177 months (range, 108-360 months).

Complete remission was reached in 269 of cases $(91.2 \%)$. Two patients had tumor recurrence $(0.7 \%), 7$ had a lymph node recurrence $(2.4 \%)$, and 4 had a distant metastasis $(1.4 \%)$. Lymph node recurrences were detected in 1 patient by iodine 131 imaging, in 4 cases by neck ultrasound, and in 2 cases on the basis of a progression of thyroglobulin levels leading to new ultrasound examinations. All patients with lymph node recurrence underwent surgery.

One patient died of their cancer. In terms of surgical complications, 35 patients had hypoparathyroidism (11.9\%), 13 had recurrent laryngeal nerve paralysis $(4.4 \%), 4$ had spinal accessory nerve injury (1.4\%), 4 had compressive cervical hematomas $(1.4 \%)$, and 6 had cervical lymphatic effusions $(2 \%)$.

\section{Comparison of $\mathrm{C}+$ and $\mathrm{C}$ - patients}

Patients, tumors, and neck dissections. There was no difference between the 2 groups in terms of age, sex, tumor size, histology, and pT classification. In the $\mathrm{C}+$ group, 
TABLE 1. Description of the population.

\begin{tabular}{|c|c|}
\hline Characteristics & Population $(n=295)$ \\
\hline Age, y & $47 \pm 13.6(19-79)$ \\
\hline Ratio men/women & $54 / 241(18.3 / 81.7)$ \\
\hline Tumor size, mm & $23.4 \pm 9.3(10-40)$ \\
\hline Papillary & $231(78.3)$ \\
\hline Vesicular & $64(21.7)$ \\
\hline \multicolumn{2}{|l|}{ Tumor distribution } \\
\hline Unifocal & $198(67.1)$ \\
\hline Multifocal & $97(32.9)$ \\
\hline \multicolumn{2}{|l|}{ TNM classification* } \\
\hline pT1a & $27(9.2)$ \\
\hline pT1b & $114(38.6)$ \\
\hline pT2 & $154(52.2)$ \\
\hline \multicolumn{2}{|l|}{$\mathrm{C}+$ patients $^{\dagger}$} \\
\hline No. of patients & $212(71.9)$ \\
\hline $\begin{array}{c}\mathrm{C}+\text { patients with lymph } \\
\text { node involvement }\end{array}$ & $72(34)$ \\
\hline $\begin{array}{l}\mathrm{C}+\text { patients without lymph } \\
\text { node involvement }\end{array}$ & $140(66)$ \\
\hline \multicolumn{2}{|l|}{ C- patients } \\
\hline No. of patients & $83(28.1)$ \\
\hline Complete remission & $269(91.2)$ \\
\hline Persistence & $26(8.8)$ \\
\hline No. of events & $13(4.4)$ \\
\hline Tumor event & $2(0.7)$ \\
\hline Lymph node event & $7(2.4)$ \\
\hline Metastatic event & $4(1.4)$ \\
\hline \multicolumn{2}{|l|}{ No. of complications } \\
\hline Permanent hypoparathyroidism & $35(11.9)$ \\
\hline Recurrent laryngeal nerve paralysis & $13(4.4)$ \\
\hline Spinal accessory nerve injury & $4(1.4)$ \\
\hline Compressive hematoma & $4(1.4)$ \\
\hline Cervical lymphatic effusion & $6(2)$ \\
\hline Death & $1(0.3)$ \\
\hline
\end{tabular}

* TNM classification $=$ Tumor, Node, and Metastatic 2010 classification.

${ }^{\dagger} \mathrm{C}+$ patients $=$ total thyroidectomy with prophylactic neck dissection.

${ }^{\ddagger} \mathrm{C}$ - patients $=$ total thyroidectomy without prophylactic neck dissection

Note: Data are expressed as mean \pm SD (range) and number (\%).

140 were classified pN0 $(66 \%)$ and 72 were pN1 $(34 \%$; including $22 \mathrm{pN} 1 \mathrm{a}$ [10.4\%] and $50 \mathrm{pN} 1 \mathrm{~b}$ [23.6\%]; Table 2). The type of neck dissection that was performed in the majority of cases was central and lateral (74.5\%), $8 \%$ had a central dissection and $17.5 \%$ had a simple lateral dissection. The average number of lymph nodes removed regardless of the dissection type was $14.2 \pm 11.2$.

Surgical complications. In the $\mathrm{C}+$ group, 4 of the patients (1.9\%) developed compressive cervical hematoma, 6 $(2.8 \%)$ suffered cervical lymphatic effusion, and $4(1.9 \%)$ had spinal accessory nerve injury. Conversely, in the Cgroup, these complications were not observed. Permanent hypoparathyroidism was found in 32 of $\mathrm{C}+$ patients $(15.1 \%)$, and in 3 of $\mathrm{C}$ - patients $(3.6 \% ; p=.006)$. Recurrent laryngeal nerve paralysis was found in 12 of $\mathrm{C}+$ patients $(5.7 \%)$ and 1 of the $\mathrm{C}$ - patients $(1.2 \% ; p=.09)$. There were no reported nosocomial infections and no perioperative deaths were observed.

Progressive disease. Complete remission was observed in $195 \mathrm{C}+$ patients $(92 \%)$ compared to $74 \mathrm{C}$ - patients $(89.2 \% ; p=.4)$. The frequency of recurrence was 7 in $\mathrm{C}+$ patients $(3.3 \%)$, and 6 in $\mathrm{C}$ - patients $(7.2 \% ; p=.1)$. Tumor recurrence was observed in $2 \mathrm{C}+$ patients $(0.9 \%)$, and no tumor recurrence was observed among $\mathrm{C}$ - patients. We observed lymph node recurrence in $4 \mathrm{C}+$ patients $(1.9 \%)$ and in $3 \mathrm{C}$ - patients $(3.6 \% ; p=.41)$. A peripheral metastasis was found in 1 patient in the $\mathrm{C}+$ group $(0.5 \%)$ compared to 3 in the $\mathrm{C}$ - group $(3.6 \% ; p=.068)$.

In this study, only $1 \mathrm{C}$ - patient died because of the papillary type of DTC.

\section{DISCUSSION}

This work was a retrospective study involving a homogeneous cohort of 295 patients, monitored in the same center with $100 \%$ complete follow-up over a long period of 14 years, presenting low-risk DTC treated with total thyroidectomy and ${ }^{131} \mathrm{I}$. In this population, there was no significant benefit of neck dissection in terms of progression and survival of patients treated for a T1 or T2 nodule suspected of being thyroid cancer, without detectable lymph nodes. However, there is a significantly greater frequency of complications, especially hypoparathyroidism, when neck dissection is performed.

Neck dissection in patients with low-risk DTC is controversial. International recommendations are divided. Indeed, the guidelines of the ATA from 2009 are not in favor of this procedure ${ }^{12}$ in low-risk DTC. Others, such as those of the National Comprehensive Cancer Network from 2012, or the Latin America Thyroid Society from 2009, the British Thyroid Association/Royal College of Physicians guidelines published in 2007 or those of the European Thyroid Association from 2006 do not take a clear position. ${ }^{14-17}$ Only the Japan Society for the Promotion of Science has recommend the practice of more aggressive surgery with prophylactic neck dissection since $2011 .^{18}$

In our study, the cumulative frequency of local, regional, and distant recurrences was low (4.4\%). Literature data is discordant in this regard. Shaha et $\mathrm{al}^{19}$ found a higher recurrence rate of $13 \%$ in the group considered low-risk: age $\leq 45$ years, tumor size $<4 \mathrm{~cm}$, no extrathyroidal extension, no metastatic disease, and papillary form. ${ }^{19,20}$ This difference could be explained by the fact that their cohort was longer (from 1930 to 1985). In addition, the patients included in the Shaha et $\mathrm{al}^{19}$ study did not all undergo total thyroidectomy.

The meta-analysis by Wang et $\mathrm{al}^{21}$ showed, as in our work, that among 1740 patients, there was no difference in terms of recurrence among those who underwent total surgical procedure (thyroidectomy and prophylactic central neck dissection) and those who underwent total simple thyroidectomy without neck dissection (respectively, $4.3 \%$ and $7.9 \% ; p=.08$ ). Yet other studies, ${ }^{19,22-25}$ including 1 report by Mazzaferri et al, ${ }^{24}$ showed that the presence of lymph node metastases increased the recurrence rate in patients, $>30$ years after initial care. However, we note that the findings of that study were based on the analysis of tumors $>1.5 \mathrm{~cm}$ without differentiating the patient risk group. Moreover, recurrences were only evaluated from the final nodal status without considering the preoperative lymph node presentation of the patient.

In our study, among all the patients, 1 death was directly related to thyroid cancer. In the literature, only 
TABLE 2. Comparison of the clinical and tumor characteristics of the $\mathrm{C}^{*}{ }^{*}$ and $\mathrm{C}-^{\dagger}$ patients.

\begin{tabular}{|c|c|c|c|}
\hline Characteristics & $\mathrm{C}+(n=212)$ & $C-(n=83)$ & $p$ value \\
\hline Age, y & $46.2 \pm 13.5(19-76)$ & $49.1 \pm 13.8(19-79)$ & .1 \\
\hline Ratio men/women & $(40 / 172)(18.9 / 81.1)$ & $(14 / 69)(16.9 / 83.1)$ & .7 \\
\hline Tumor size, mm & $23.4 \pm 9.3(10-40)$ & $23.4 \pm 9.1(10-40)$ & .9 \\
\hline Papillary & $170(80.2)$ & $61(73.5)$ & .2 \\
\hline Vesicular & $42(19.8)$ & $22(26.5)$ & .2 \\
\hline \multicolumn{4}{|l|}{ Tumor distribution } \\
\hline Unifocal & $143(67.5)$ & $55(66.2)$ & .8 \\
\hline Multifocal & $69(32.6)$ & $28(33.7)$ & .8 \\
\hline \multicolumn{4}{|l|}{ TNM classification } \\
\hline pT1a & $22(10.4)$ & $5(6)$ & .36 \\
\hline pT1b & $80(37.7)$ & $34(41)$ & .8 \\
\hline pT2 & $110(51.9)$ & $44(53)$ & .91 \\
\hline \multicolumn{4}{|l|}{ Lymph node distribution ${ }^{\S}$} \\
\hline NO & $140(66)$ & - & - \\
\hline $\mathrm{N} 1 \mathrm{a}$ & $22(10.4)$ & - & - \\
\hline $\mathrm{N} 1 \mathrm{~b}$ & $50(23.6)$ & - & - \\
\hline Complete remission & $195(92)$ & 74 (89.2) & .4 \\
\hline Persistence & $17(8)$ & $9(10.8)$ & .4 \\
\hline \multicolumn{4}{|l|}{ Events } \\
\hline Number & $7(3.3)$ & $6(7.2)$ & .1 \\
\hline Tumor event & $2(0.9)$ & $0(0)$ & - \\
\hline Lymph node event & $4(1.9)$ & $3(3.6)$ & .41 \\
\hline Metastatic event & $1(0.5)$ & $3(3.6)$ & .068 \\
\hline \multicolumn{4}{|l|}{ Complications } \\
\hline Permanent hypoparathyroidism & $32(15.1)$ & $3(3.6)$ & .006 \\
\hline Recurrent laryngeal nerve paralysis & $12(5.7)$ & $1(1.2)$ & .09 \\
\hline Spinal accessory nerve injury & $4(1.9)$ & $0(0)$ & - \\
\hline Compressive hematoma & $4(1.9)$ & $0(0)$ & - \\
\hline Cervical lymphatic effusion & $6(2.8)$ & $0(0)$ & - \\
\hline Death & $0(0)$ & $1(1.2)$ & - \\
\hline
\end{tabular}

${ }^{*} \mathrm{C}+=$ total thyroidectomy with prophylactic neck dissection.

${ }^{\dagger} \mathrm{C}-=$ total thyroidectomy without prophylactic neck dissection.

${ }^{\ddagger}$ TNM classification = Tumor, Node, and Metastatic 2010 classification.

$\S$ Lymph node distribution by TNM 2010 classification.

Note: Data are expressed as mean \pm SD (range) and number (\%).

the study by Tisell et $\mathrm{al}^{26}$ in 195 patients showed a beneficial effect of prophylactic neck dissection on patients' survival. These results have never been confirmed since, whereas several studies have confirmed that prophylactic neck dissection does not yield any benefits in terms of survival. ${ }^{19,22-25,27,28}$ These results seem surprising because, in the absence of "prophylactic" neck dissection, involved lymph nodes were left in $35 \%$ to $72.7 \%$ of the patients. ${ }^{10,11}$ Two hypotheses have been proposed to explain the lack of benefit on survival despite the high rate of lymph node involvement (up to $80 \%$ of involved lymph nodes taking into account the micrometastases ${ }^{29}$ ).

The first is that a certain number of these metastases remain dormant and do not progress into more aggressive forms. ${ }^{30}$

The second potential explanation is related to the adjuvant therapy with ${ }^{131} \mathrm{I}$, which could eliminate most of these lymph node micrometastases, thereby preventing their short-term, medium-term, or long-term repercussion on survival. ${ }^{31}$

Some authors have shown that although the absence of prophylactic neck dissection can favor the occurrence of lymph node recurrences, ${ }^{32}$ these local recurrences do not worsen the prognosis of patients with a low-risk differentiated cancer. $^{24,33,34}$ These lymph node recurrences generally remain localized and are treated surgically. This explains why lymph node involvement is not recognized as a prognostic factor of survival and is therefore not included in the prognostic classification of patients with DTC, such as the age, distant metastases other than neck lymph nodes, extent of primary tumor, size of the tumor (AMES), age, tumor grade, extent, and size (AGES), and metastases, patient age, completeness of resection, local invasion, and tumor size (MACIS) classifications. ${ }^{24,25,35,36}$

In our study, hypoparathyroidism was the leading cause of surgical morbidity, and was significantly more frequent in case of prophylactic neck dissection $(\mathrm{C}+: 15.1 \%)$ than in its absence (C-: $\left.3.6 \% ; \mathrm{p}=0.006^{*}\right)$. This frequency is higher than that reported in the literature, which ranged from $4 \%$ to $7 \%$ after neck dissection and from $0 \%$ to $2 \%$ without neck dissection dissection, ${ }^{27,37}$ except for the only recent prospective study ${ }^{38}$ in which the permanent hypoparathyroidism rate was significantly higher in case of prophylactic neck dissection $(19.4 \%$ vs $8 \% ; p=.02)$.

One hypothesis to help explain this difference is that the definition of hypoparathyroidism is not homogeneous in all studies. It is sometimes determined 6 months after the initial surgery ${ }^{39,40}$ and sometimes 12 months after. ${ }^{41}$ The difference of $1 \%$ to $12 \%$ between the reported rates of hypoparathyroidism by English surgeons evaluated by the British Association of Endocrine and Thyroid Surgeon, highlights this finding. ${ }^{42}$ 
Recurrent laryngeal nerve paralysis and spinal accessory nerve injury are the other 2 main causes of morbidity. Their frequencies were equivalent between $\mathrm{C}+$ and $\mathrm{C}$ - groups. We found that the rate of recurrent laryngeal nerve paralysis reported in the literature was lower than that observed in our study only in case of neck dissection (5.7\% found in our study vs 0 to $3.6 \%$ in the literature if $\mathrm{C}+$; and $1.2 \%$ found in our study vs 0 to $2.7 \%$ in the literature for C-). ${ }^{37,43}$ Regarding spinal accessory nerve injury, the rate is consistent with that of the literature ( $1.4 \%$ found in our study vs $1.7 \%$ in the literature) ${ }^{44}$

The prophylactic neck dissection is therefore likely the cause of significant morbidity ${ }^{26,45-50}$ although there is no benefit in terms of survival. Some authors recommend performing a diagnostic neck dissection in the area where lymph node involvement is the most common, at the level VI compartment, ${ }^{45,51,52}$ in order to determine the patient's lymph node status. ${ }^{17}$ This allows for the adaptation of therapeutic management by further treatment with ${ }^{131} \mathrm{I}$ according to the presence or absence of lymph node involvement.

In our study, all patients, whether $\mathrm{C}+$ or $\mathrm{C}-$, received additional treatment with ${ }^{131} \mathrm{I}$. At that time, treatment by radioactive iodine 131 therapy was indicated for thyroid cancers $>10 \mathrm{~mm}$ with a good prognosis. The recommendations and indications for ${ }^{131} \mathrm{I}$ therapy have been refined over the years, and are different now to what they were during the study period. Indeed, we previously showed elsewhere that iodine 131 therapy does not impact on survival of patients with low-risk DTC classified pT1/ pT2NXM0 after more than 10 years of follow-up. ${ }^{53}$

We also noted that iodine 131 treatment, which has the ability of destroying lymph node micrometastases especially in the absence of neck dissection, may explain why, in our population, recurrence rates are not very different between $\mathrm{C}+$ and $\mathrm{C}$ - patients.

Although it would not be impossible to perform prospective studies to evaluate the potential utility of neck dissection in DTC, the number of patients required, the follow-up period, and the cost of these studies represent major obstacles. ${ }^{54}$ A feasibility study was conducted in 2011 by the $\mathrm{ATA}^{54}$ to assess the possibility of a randomized clinical trial on the interest of prophylactic central neck dissection in patients with DTC without any preoperatively documented lymph node involvement. However, it was calculated that 5840 patients would need to be included to show a decrease of $3 \%$ per year in the central neck dissection group, and, therefore, the implementation of such a trial was deemed impossible.

However, a prospective study, ${ }^{38}$ with a total of 181 patients followed up for 60 months, demonstrated that a prophylactic neck dissection did not provide any benefit in terms of survival or a decrease in recurrences. On the contrary, it induced a significant increase in hypoparathyroidism ( $8 \%$ vs $19.4 \% ; p=.02$ ). The authors drew similar conclusions to ours concerning the lack of utility of prophylactic neck dissection in patients with a DTC without detectable lymph nodes.

\section{CONCLUSIONS}

In our study, the risk-benefit analysis of prophylactic neck dissection in patients with low-risk DTC, without lymph nodes detected in the preoperative examination, and treated by total thyroidectomy and ${ }^{131} \mathrm{I}$, is not in favor of performing neck dissection because of its high morbidity and low rate of progression observed during follow-up.

\section{REFERENCES}

1. Mortensen JD, Woolner LB, Bennett WA. Gross and microscopic findings in clinically normal thyroid glands. J Clin Endocrinol Metab 1955;15: 1270-1280.

2. Wiest PW, Hartshorne MF, Inskip PD, et al. Thyroid palpation versus highresolution thyroid ultrasonography in the detection of nodules. J Ultrasound Med 1998;17:487-496.

3. Carroll BA. Asymptomatic thyroid nodules: incidental sonographic detection. AJR Am J Roentgenol 1982;138:499-501.

4. Brander A, Viikinkoski P, Nickels J, Kivisaari L. Thyroid gland: US screening in a random adult population. Radiology 1991;181:683-687.

5. Bruneton JN, Balu-Maestro C, Marcy PY, Melia P, Mourou MY. Very high frequency $(13 \mathrm{MHz})$ ultrasonographic examination of the normal neck: detection of normal lymph nodes and thyroid nodules. J Ultrasound Med 1994; 13:87-90.

6. Katz SC, Shaha A. PET-associated incidental neoplasms of the thyroid. J Am Coll Surg 2008;207:259-264.

7. Iyer NG, Shaha AR. Management of thyroid nodules and surgery for differentiated thyroid cancer. Clin Oncol (R Coll Radiol) 2010;22:405-412.

8. Sciuto R, Romano L, Rea S, Marandino F, Sperduti I, Maini CL. Natural history and clinical outcome of differentiated thyroid carcinoma: a retrospective analysis of 1503 patients treated at a single institution. Ann Oncol 2009;20:1728-1735.

9. Bilimoria KY, Bentrem DJ, Ko CY, et al. Extent of surgery affects survival for papillary thyroid cancer. Ann Surg 2007;246:375-381; discussion 381-384.

10. Vergez S, Sarini J, Percodani J, Serrano E, Caron P. Lymph node management in clinically node-negative patients with papillary thyroid carcinoma. Eur J Surg Oncol 2010;36:777-782.

11. Arch-Ferrer J, Velázquez D, Fajardo R, Gamboa-Domínguez A, Herrera MF. Accuracy of sentinel lymph node in papillary thyroid carcinoma. Surgery 2001;130:907-913.

12. American Thyroid Association (ATA) Guidelines Taskforce on Thyroid Nodules and Differentiated Thyroid Cancer, Cooper DS, Doherty GM, et al. Revised American Thyroid Association management guidelines for patients with thyroid nodules and differentiated thyroid cancer. Thyroid 2009; 19:1167-1214.

13. Edge SB, Byrd DR, Compton C, Fritz AG, Greene FL, Trotti A III, editors. AJCC Cancer Staging Manual. 7th ed. New York, NY: Springer; 2010.

14. Tuttle RM, Ball DW, Byrd D, et al. NCCN Clinical Practice Guidelines in Oncology, version 3.2011. Available at: http://www.lecba-rakoviny.cz/ dokumenty/NCCN_Guidelines thyroid 2011.pdf. Accessed July 15, 2015.

15. Pitoia F, Ward L, Wohllk N, et al. Recommendations of the Latin American Thyroid Society on diagnosis and management of differentiated thyroid cancer. Arq Bras Endocrinol Metabol 2009;53:884-887.

16. British Thyroid Association, Royal College of Physicians of London. Guidelines for the management of thyroid cancer. Available at: http:// www.british-thyroid-association.org/news/Docs/Thyroid_cancer_guidelines_2007.pdf. Accessed July 15, 2015.

17. Pacini F, Schlumberger M, Dralle H, et al. European consensus for the management of patients with differentiated thyroid carcinoma of the follicular epithelium. Eur J Endocrinol 2006;154:787-803.

18. Takami H, Ito Y, Okamoto T, Yoshida A. Therapeutic strategy for differentiated thyroid carcinoma in Japan based on a newly established guideline managed by Japanese Society of Thyroid Surgeons and Japanese Association of Endocrine Surgeons. World J Surg 2011;35:111-121.

19. Shaha AR, Shah JP, Loree TR. Patterns of failure in differentiated carcinoma of the thyroid based on risk groups. Head Neck 1998;20:26-30.

20. Grebe SK, Hay ID. Thyroid cancer nodal metastases: biologic significance and therapeutic considerations. Surg Oncol Clin N Am 1996;5:43-63.

21. Wang TS, Cheung K, Farrokhyar F, Roman SA, Sosa JA. A meta-analysis of the effect of prophylactic central compartment neck dissection on locoregional recurrence rates in patients with papillary thyroid cancer. Ann Surg Oncol 2013;20:3477-3483.

22. Harwood J, Clark OH, Dunphy JE. Significance of lymph node metastasis in differentiated thyroid cancer. Am J Surg 1978;136:107-112.

23. Mazzaferri EL, Young RL. Papillary thyroid carcinoma: a 10 year followup report of the impact of therapy in 576 patients. Am J Med 1981;70:511518 .

24. Mazzaferri EL, Jhiang SM. Long-term impact of initial surgical and medical therapy on papillary and follicular thyroid cancer. Am J Med 1994;97: $418-428$.

25. Hay ID, Bergstralh EJ, Goellner JR, Ebersold JR, Grant CS. Predicting outcome in papillary thyroid carcinoma: development of a reliable prognostic scoring system in a cohort of 1779 patients surgically treated at one institution during 1940 through 1989. Surgery 1993;114:1050-1057; discussion 1057-1058. 
26. Tisell LE, Nilsson B, Mölne J, et al. Improved survival of patients with papillary thyroid cancer after surgical microdissection. World J Surg 1996; 20:854-859.

27. Bardet S, Malville E, Rame JP, et al. Macroscopic lymph-node involvement and neck dissection predict lymph-node recurrence in papillary thyroid carcinoma. Eur J Endocrinol 2008;158:551-560.

28. Roh JL, Park JY, Park CI. Total thyroidectomy plus neck dissection in differentiated papillary thyroid carcinoma patients: pattern of nodal metastasis, morbidity, recurrence, and postoperative levels of serum parathyroid hormone. Ann Surg 2007;245:604-610.

29. Gimm O, Rath FW, Dralle H. Pattern of lymph node metastases in papillary thyroid carcinoma. Br J Surg 1998;85:252-254.

30. Cranshaw IM, Carnaille B. Micrometastases in thyroid cancer. An important finding? Surg Oncol 2008;17:253-258.

31. Grubbs EG, Rich TA, Li G, et al. Recent advances in thyroid cancer. Curr Probl Surg 2008;45:156-250.

32. Machens A, Hinze R, Thomusch O, Dralle H. Pattern of nodal metastasis for primary and reoperative thyroid cancer. World J Surg 2002;26:22-28.

33. Rossi RL, Cady B, Silverman ML, Wool MS, Horner TA. Current results of conservative surgery for differentiated thyroid carcinoma. World J Surg 1986;10:612-622.

34. Hughes CJ, Shaha AR, Shah JP, Loree TR. Impact of lymph node metastasis in differentiated carcinoma of the thyroid: a matched-pair analysis. Head Neck 1996; 18:127-132.

35. Cady B, Rossi R. An expanded view of risk-group definition in differentiated thyroid carcinoma. Surgery 1988;104:947-953.

36. Byar DP, Green SB, Dor P, et al. A prognostic index for thyroid carcinoma. A study of the E.O.R.T.C. Thyroid Cancer Cooperative Group. Eur J Cancer 1979;15:1033-1041.

37. Henry JF, Gramatica L, Denizot A, Kvachenyuk A, Puccini M, Defechereux T. Morbidity of prophylactic lymph node dissection in the central neck area in patients with papillary thyroid carcinoma. Langenbecks Arch Surg 1998;383:167-169.

38. Sturgeon C. Randomized, prospective trial finds no clinical advantage to prophylactic central-neck dissection for papillary thyroid cancer. Clin Thyroidol 2015;27:48-50.

39. Bilezikian JP, Khan A, Potts JT Jr, et al. Hypoparathyroidism in the adult: epidemiology, diagnosis, pathophysiology, target-organ involvement, treatment, and challenges for future research. J Bone Miner Res 2011;26:2317-2337.

40. Shoback D. Clinical practice. Hypoparathyroidism. N Engl J Med 2008; 359:391-403.

41. Glinoer D, Andry G, Chantrain G, Samil N. Clinical aspects of early and late hypocalcaemia after thyroid surgery. Eur J Surg Oncol 2000;26:571-577.
42. Chadwick D, Kinsman R, Walton P. The British Association of Endocrine and Thyroid Surgeons, fourth national audit report, 2012. Available at: http://www.baets.org.uk/wp-content/uploads/2013/05/4th-National-Audit. pdf. Accessed July 15, 2015.

43. Roh JL, Park JY, Rha KS, Park CI. Is central neck dissection necessary for the treatment of lateral cervical nodal recurrence of papillary thyroid carcinoma? Head Neck 2007;29:901-906.

44. Kraus DH, Rosenberg DB, Davidson BJ, et al. Supraspinal accessory lymph node metastases in supraomohyoid neck dissection. Am J Surg 1996; 172:646-649.

45. Wang Q, Chu B, Zhu J, et al. Clinical analysis of prophylactic central neck dissection for papillary thyroid carcinoma. Clin Transl Oncol 2014;16: 44-48.

46. Sywak M, Cornford L, Roach P, Stalberg P, Sidhu S, Delbridge L. Routine ipsilateral level VI lymphadenectomy reduces postoperative thyroglobulin levels in papillary thyroid cancer. Surgery 2006;140:1000-1005; discussion 1005-1007.

47. Palestini N, Borasi A, Cestino L, Freddi M, Odasso C, Robecchi A. Is central neck dissection a safe procedure in the treatment of papillary thyroid cancer? Our experience. Langenbecks Arch Surg 2008;393:693-698.

48. Kim MK, Mandel SH, Baloch Z, et al. Morbidity following central compartment reoperation for recurrent or persistent thyroid cancer. Arch Otolaryngol Head Neck Surg 2004;130:1214-1216.

49. Moley JF, Lairmore TC, Doherty GM, Brunt LM, DeBenedetti MK. Preservation of the recurrent laryngeal nerves in thyroid and parathyroid reoperations. Surgery 1999;126:673-677; discussion 677-679.

50. Lundgren CI, Hall P, Dickman PW, Zedenius J. Clinically significant prognostic factors for differentiated thyroid carcinoma: a population-based, nested case-control study. Cancer 2006;106:524-531.

51. Roh JL, Kim JM, Park CI. Central compartment reoperation for recurrent/ persistent differentiated thyroid cancer: patterns of recurrence, morbidity, and prediction of postoperative hypocalcemia. Ann Surg Oncol 2011;18: 1312-1318.

52. Robbins KT, Shaha AR, Medina JE, et al. Consensus statement on the classification and terminology of neck dissection. Arch Otolaryngol Head Neck Surg 2008; 134:536-538.

53. Schvartz C, Bonnetain F, Dabakuyo S, et al. Impact on overall survival of radioactive iodine in low-risk differentiated thyroid cancer patients. J Clin Endocrinol Metab 2012:97:1526-1535.

54. Carling T, Carty SE, Ciarleglio MM, et al. American Thyroid Association design and feasibility of a prospective randomized controlled trial of prophylactic central lymph node dissection for papillary thyroid carcinoma. Thyroid 2012;22:237-244. 